\title{
Influence of Various Process Parameters on the Density of Sintered Aluminium Alloys
}

\author{
Mateusz Laska ${ }^{1}$, Jan Kazior ${ }^{1}$ \\ ${ }^{1}$ Cracow Univeristy of Technology, ul. Warszawska 24, 31-155 Krakow \\ Correspondence to: mgrmlaska@gmail.com
}

\begin{abstract}
This paper presents the results of density measurements carried out on Alumix sintered parts. ECKA Alumix aluminium powders were used because of their wide application in the powder metallurgy industry. The compacts were produced using a wide range of compaction pressures for three different chemical compositions. The compacts were then sintered under a pure dry nitrogen atmosphere at three different temperatures. The heating and cooling rates were the same throughout the entire test. The results showed that the green density increases with compaction pressure, but that sintered density is independent of green density (compaction pressure) for each sintering temperature.
\end{abstract}

Keywords: Alumix, sintering, powder metallurgy, density.

\section{Introduction}

PM aluminium alloys have growing potential in the automotive industry, because desired properties of structural components can be achieved at relatively low cost. In recent times, considerable efforts have been made to develop $\mathrm{AlZnMgCu}$ sintered alloys. The alloying elements were introduced as elemental powders, or in the form of master alloys, since prealloyed powders are incompressible and cause some technological problems during sintering. However, developments in aluminium-silicon alloys remain an area of intense interest. In principle, silicon additions are made to aluminium casting alloys in order to increase the fluidity of the molten alloy. The addition of silicon to aluminum alloys in PM technology offers some advantages in the production cycle over casting, in particularly in its ability to produce hypereutectic alloys with a relatively fine silicon particle, which can for example provide wear-resistant products. With the use of proper sintering parameters, densities of almost $99 \%$ of the theoretical density can be achieved [1-5]. The powders used in this paper were produced by ECKA Granules, under the designation ECKA Alumix. EA231, EA 321 and EA 431D were used. The purpose of this research work was to study the influence of various process parameters on the densification behavior of various aluminium alloy powders.

\section{Experimental procedure}

The powders used in this study were EA231, EA 321 and EA 431D, supplied by ECKA. The characteristics of the powders are summarized in Table 1 . The powder mixtures were uniaxially pressed in steel dies at 450, 500, 550 and $600 \mathrm{MPa}$ compaction pressure to obtain cylindrical samples $20 \mathrm{~mm}$ in diameter and 5 $\mathrm{mm}$ in height. The sintering process was carried out at temperatures of 580,590 and $600{ }^{\circ} \mathrm{C}$ for 30 minutes, under pure dry nitrogen. The heating and cooling rates were set at a constant level of $5^{\circ} \mathrm{C} / \mathrm{min}$. The densities of the green compacts were determined from the mass and the dimensions of the compacts, while the densities of the sintered compacts were determined using the Archimedes principle. The theoretical density (TD ) was calculated using the simplified additive function, applying the formula:

$$
T D=\frac{100}{\frac{P 1}{D 1}+\frac{P 2}{D 2}+\ldots+\frac{P x}{D x}}
$$

Where the $T D$ is Theoretical Density, $P x$ is mass percentage of respective elements, $D x$ is density of the respective ingredients in elementary form.

A Netzsch 402C dilatometer was used for determining the dimensional changes during sintering, and $15 \times 5 \times 5$ prismatic specimens were sintered under the same conditions as the cylindrical specimens.

Table 1: Chemical compositions and theoretical densities

\begin{tabular}{|lccccccc|}
\hline Material & $\mathrm{Cu}$ (wt. \%) & $\mathrm{Mg}$ (wt. \%) & $\mathrm{Si}($ wt. \%) & Zn (wt. \%) & Wax (wt. \%) & $\mathrm{Al}($ wt. \%) & $T D\left(\mathrm{~g} / \mathrm{cm}^{3}\right)$ \\
\hline EA231 & 2.5 & 0.5 & 14 & - & 1.5 & Balance & 2.68 \\
EA321 & 0.2 & 1 & 0.5 & - & 1.5 & Balance & 2.69 \\
EA431 & 1.5 & 2.5 & - & 5.5 & 1 & Balance & 2.79 \\
\hline
\end{tabular}




\section{Results and discussion}

Figure 1 presents density measurements as a function of compaction pressure. It is evident that green density increases with compaction pressure. However, for the same compaction pressure the green density is different, due to differences in chemical compositions, in particular in the amount of silicon and copper in the powders under study here. Figure 2 presents the relationship between sintered density and compaction pressure for different sintering temperatures. It was observed that while the green density increases with compaction pressure, the sintered density is independent of the green density (compaction pressure) for each sintering temperature.

Additionally, the densification factor for all sintered specimens was defined, using the formula:

$$
D F=\frac{S d-G d}{T d-G d}
$$

where $D F$ is densification factor, $S d$ is sintered density, $G d$ is green density, and $T d$ is theoretical density. A negative densification coefficient indicates expansion, while a positive value represents shrinkage. The relationship between densification factor and compaction pressure is presented in Figure 3 . The fact that both powders containing silicon (EA231 and EA321) have a densification factor significantly lower (samples expanded) than the EA431 powder containing zinc (shrinkage after sintering) leads to the conclusion that the two different groups of powders behave in different ways during sintering.

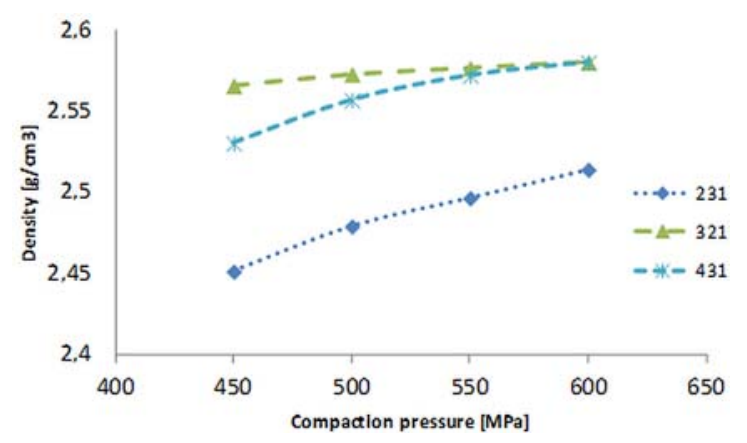

Figure 1: Influence of compaction pressure on the green densities of compacts

It is interesting to note that, in principle, the trend of the densification factor is lower for higher compaction pressures. This does not apply, however, for the sample of EA431 compacted at $600 \mathrm{MPa}$ and sintered at $590{ }^{\circ} \mathrm{C}$, and this phenomenon will be a topic for further study. Figure 4 presents a typical dilatometric curve for EA431. Dilatometry indicates that samples undergo significant dimensional changes during different parts of the sintering cycle. The specimens expand rapidly just before isothermal sintering and then shrink during isothermal sintering and cooling. The peak of expansion could be related to penetration of the liquid phase by the interparticle capillaries, which forces the sample apart. The shrinkage during sintering is a result of densification mechanisms, and during cooling it is a result of thermal contraction.
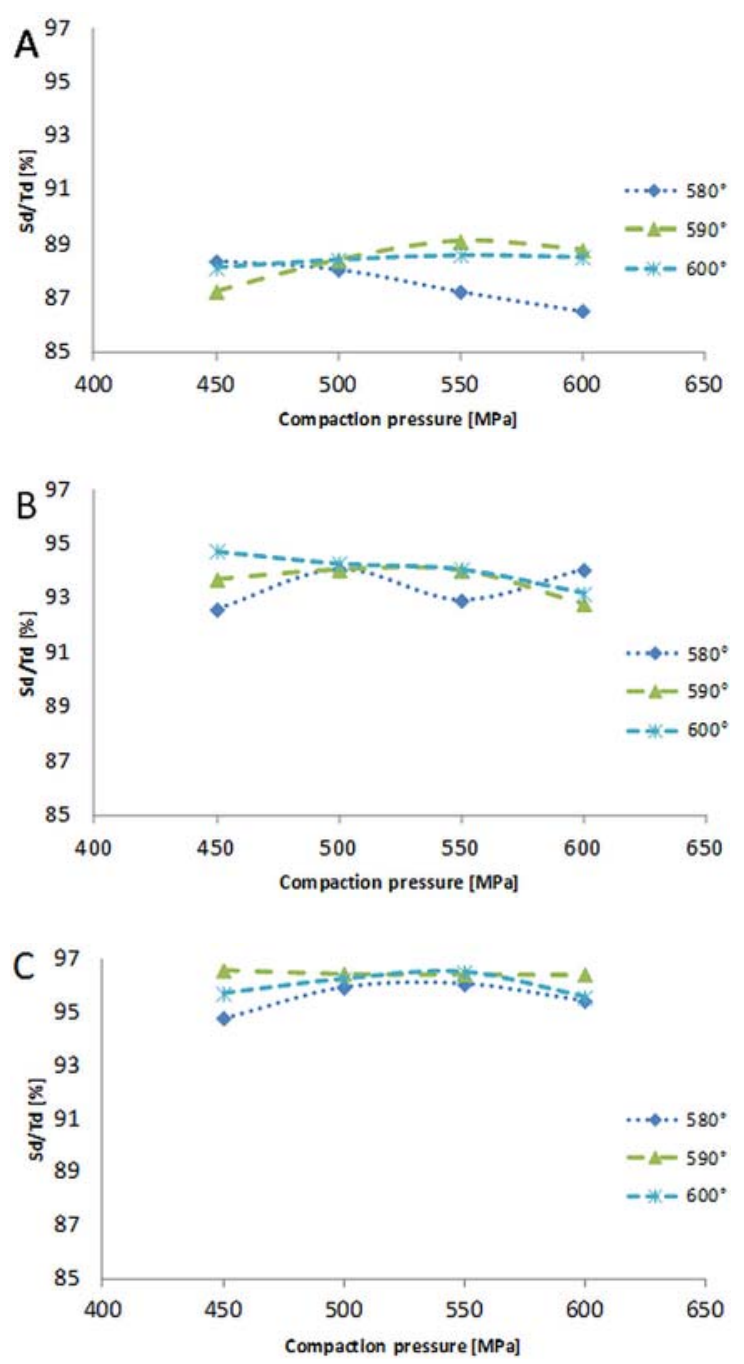

Figure 2: Sintered density to theoretical density ratio as a function of compaction pressure for: (A) EA231, (B) EA321, (C) EA431

The negative values of the densification factor curves of the EA231 and EA321 powders therefore correspond with the observed changes in the geometry of the samples and the swelling of the sintered parts. General observations of the surface showed that the faces of samples EA231 and EA321 were rough, unlike the smooth surfaces of the EA431 specimens.

Further investigations are necessary for a better understanding of all the dimensional changes and the whole densification mechanism as a function of the chemical composition of aluminium alloys. 

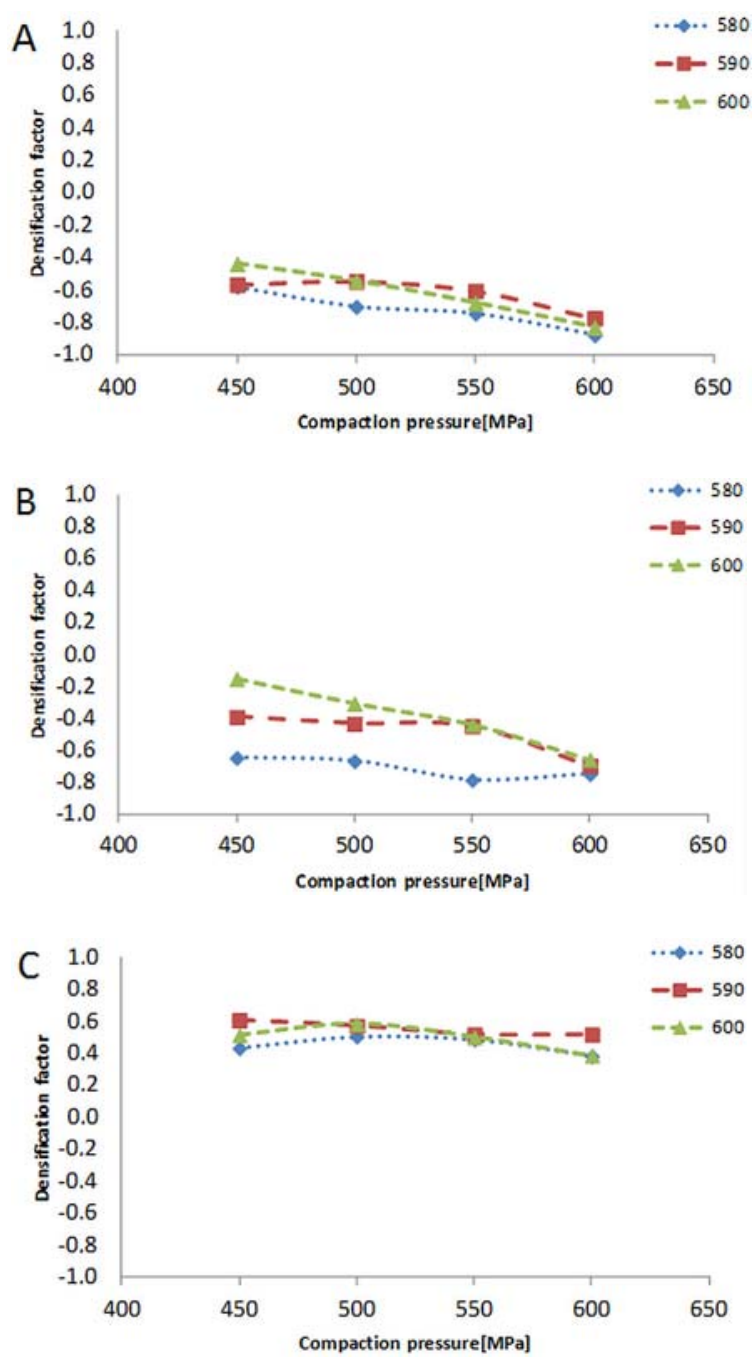

Figure 3: Densification factor as a function of compaction pressure for: (A) EA231, (B) EA321, (C) EA431

\section{Conclusion}

An evaluation of the influence of compaction pressure and sintering temperature on the density of different sintered aluminium alloys shows that these parameters do not affect the densification process of the alloy powders under study here. The EA231 and EA321 powders have significantly lower densification rates than EA431. In all cases, the EA231 and EA321 parts had lower density than their green compacts.

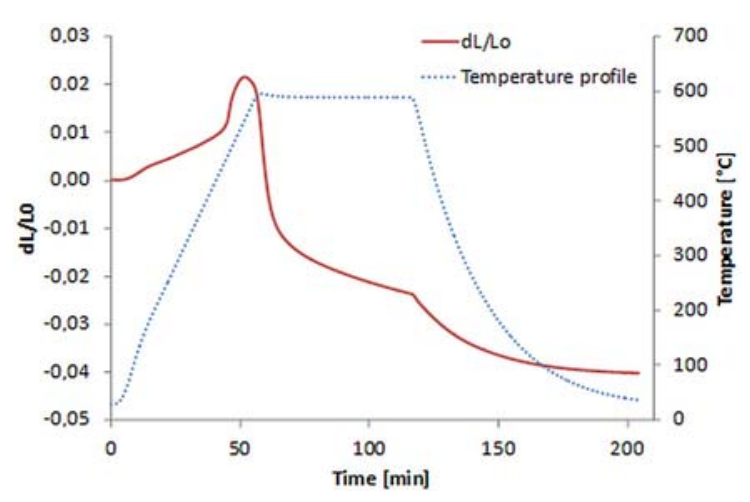

Figure 4: Dilatometric curve as a function of process time and temperature for EA431, compaction pressure $600 \mathrm{MPa}$

This can be partially explained by the swelling of the samples. The EA431 powder showed not only a positive densification factor, but also the smoothest surface of all the investigated specimens.

\section{Acknowledgement}

This research was supported by project European Funds Portal - Innovative Economy POIG No. 01.01.02-00-015/09-00

\section{References}

[1] Martin, J. M., Castro, F.: Liquid phase sintering of $\mathrm{P} / \mathrm{M}$ aluminium alloys: effect of processing conditions. In Journal of Materials Processing Technology, 2003, Vol. 143-144, p. 814-821. ISSN 0924-0136.

[2] Mondolfo, L.F.: Aluminium alloys: Structure and properties. London : Butterworths, 1976.

[3] ASM Specialty Handbook, Aluminium and Aluminium Alloys, Materials Park, OH, USA, 1993.

[4] Greasley, A., Shi, H. Y.: Powd. Metall. 36 (1993) 288.

[5] Jatkar, A. D., Sawtell, R. R.: Proceedings of the International Conference on $P / M$ Aerospace $M a-$ terials, Paper 15, Lausanne, 1991. 